\title{
Interposisi Colon Retrosternal dan Esofagoplasty Pada Pasien Atresia Esophagus Tipe A Long Gap
}

\author{
Muhammad Rifki ${ }^{1}$, Rahmens Syamun ${ }^{1}$, Jon Efendi ${ }^{2}$
}

\begin{abstract}
Abstrak
Atresia esophagus merupakan kelainan kongenital yaitu tidak menyambungnya esofagus bagian proksimal dengan esofagus bagian distal. Transposisi colon telah lama dilakukan. Colon dapat diletakkan substerrnal atau dibelakang hilum dari paru, bisa juga diletakkan retrosternal. Angka keberhasilan tindakan ini masih rendah. Dilaporkan seorang perempuan yang didiagnosa dengan atresia esophagus tipe $A$ saat berumur satu hari, pemeriksaan ditegakkan melalui pemeriksaan $\mathrm{x}$ ray dimana dilakukan pemasangan OGT dengan contras, pada pasien dilakukan tindakan esofagotomi dan gastrostomi. Kondisi membaik, tidak ditemui kelainan kongenital lain. Pasien bertahan sampai umur 1 tahun 6 bulan, kemudian dilakukan tindakan transposisi colon retrosternal dan esofagoplasty. Pasien diberikan TPN (Total Per Enteral), diet enteral dimulai hari ke-6 dan dinaikkan secara bertahap. Pasien dipulangkan hari ke 14 dengan kondisi luka baik dan pasien sudah diberikan makanan lunak. Pasca operasi transposisi colon retrosternal dan esofagoplasty pada pasien dengan atresia esophagus tipe A post esofagotomi dan gastrostomi tidak ditemukan adanya komplikasi kebocoran anastomose. Transposisi colon retrosternal dan esofagoplasty pada pasien dengan atresia esophagus tipe A post esofagostomi dan gastrostomi dengan penangan post operatif yang baik dapat memberikan hasil yang baik.
\end{abstract}

Kata kunci: atresia esophagus, esofagoplasty, transpsosisi colon retrosternal

\section{Abstract}

Esophageal atresia is a congenital disorder when no conection betwen proximal esophageal to the distal esophagus. Transposition of the colon has been carried out. Colon can pull in substerrnal or behind the hilum of the lung, can also be placed retrosternal. The succesfull rate of this operation is still rare. Case report, female patient who was diagnosed with esophageal atresia type $A 1$ day after birth, diagnosed was comformed by the $x$ ray examination which contras in OGT. Performed gasitostomy and esofagotomi. No other congenital disorder. Patient survived. At 1 year 6 months we performed colonic transposition retrosternal and esofagoplasty. Patients were given TPN, enteral diet begins at day 6 post operation and increased gradually. Patients were discharged at day 14 with good wound condition and the patient was given food orally. Follow-up postoperative retrosternal colon transposition and esofagoplasty in patients with esophageal atresia type A post esofagotomi and gastrostomy did not reveal any leakage complications anastomose. Transposition and esofagoplasty retrosternal colon in patients with esophageal atresia type A post esofagotomi and postoperative gastrostomy with a good follow up will give a good results.

Keywords: esophageal atresia, esofagoplasty, transpsosition retrosternal colon

Affiliasi penulis: 1. Program Pendidikan Dokter Spesialis Bedah FK Unand, 2. Bagian Bedah Divisi Bedah Anak FK Unand/RSUP Dr. M. Djamil, Padang.

Korespondensi: Muhammad Rifki, Email: rifki_dr@yahoo.com HP: 085263512315

\section{PENDAHULUAN}

Patogenesis Atresia Esophagus (AE) congenital masih belum diketahui. Dikatakan etiologi bersifat heterogen, multifaktorial,dan melibatkan interaksi genlingkungan yang kompleks. ${ }^{1}$ 
Pemahaman yang jelas tentang patogenesis malformasi AE dikaburkan dengan kenyataan bahwa embriologi foregut normal masih samar-samar. Wilhem his, Sr penemu embriologi manusia, yang pertama memaparkan perkembangan normal dari system pernafasan meyakini bahwa pemisahan foregut adalah hasil dari penyatuan daerah longitudinal lateral yang menghasilkan septum yang membagi foregut ke bagian dorsal dan system respirasi ke bagian ventral. Pembentukan ini dinamakan septum trakeoesofageal yang dipercaya dimulai dari kaudal dan berakhir di cranial. Reinvestigasi pada specimen manusia dari collection of embryos at the carneige institute menyarankan bahwa pada pertumbuhan dinding foregut lateral dan pertumbuhan cranial dari septum trakeoesofageal tidak terjadi pada embrio manusia. ${ }^{2,3}$

Teori tentang oklusi foregut dan kegagalan rekanalisasi dari lumen intestinal telah menjadi diskusi yang berhubungan degnan patogenesisi atresia intestinal, termasuk AE. ${ }^{3}$ Laporan mengenai insidensi AE dengan ataupun tanpa TEF (trakeoesophageal fistel) bervariasi. ${ }^{4}$

\section{Klasifikasi}

Klasifikasi gross masih sering dipakai oleh institusi dan ahli bedah.

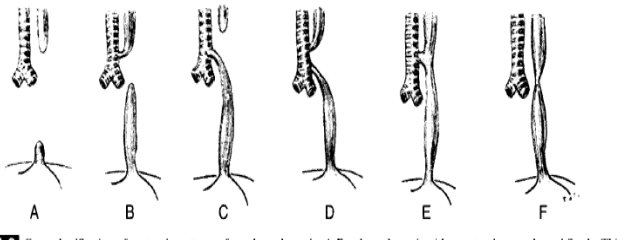

Gambar 1. Gross Classification of anatomic pattern of esophageal atresia ${ }^{2}$

\section{Diagnosis}

Tidak seperti masalah bedah anak kongenital lainnya, $A E$ prenatal jarang terdiagnosis. Deteksi $A E$ prenatal dengan USG bergantung pada temuan sebuah gelembung yang kecil atau tidak adanya buble pada lambung dan berhubungan dengan polihidramnion pada ibu. Namun dengan kriteria ini, diagnosis AE hanya $20-40 \% .{ }^{1,5}$
Kebanyakan bayi dengan $A E$ menunjukkan gejala pada jam-jam pertama kehidupannya. Tanda klinis yang paling awal adalah hpersalivasi, biasanya pemberian makan pertama diikuti muntah, tersedak, dan batuk. Gejala lainnya adalah sianosis dengan atau tanpa makan, sesak nafas, kesulitan menelan, dan ketidakmampuan makanan atau kateter suction masuk ke lambung. Jika ditemukan fistel bagian distal, perut akan kembung saat inspirasi. Gangguan pulmonary akan terjadi jika cairan lambung naik melewati TEF, mengisi trakea dan paru dan selanjutnya menyebabkan pneumonitis kimia. Dengan perut yang makin kembung, diafragma akan naik dan pernafasan maikin terganggu. Aspirasi dari saliva pada kantung atas trakea lebih lanjut akan memicu gangguan pulmonar. ${ }^{4}$

Diagnosis AE dapat dipastikan dengan melewatkan sebuah kateter yang kaku melalui mulut ke dalam esophagus pada sebuah titik dimana ada tahanan dijumpai. Beberapa millimeter udara dapat diinjeksikan melalui tube dan digunakan sebagai agen kontras untuk melebarkan bagian atas esophagus agar dapat diperoleh film dari bagian depan dan lateral. ${ }^{2}$ Jika diperlukan, $0.5 \mathrm{ml}$ hingga $1 \mathrm{ml}$ barium yang telah diencerkan dapat digunakan sebagai kontras dan disuntikan ke bagian atas untuk konfirmasi diagnosis. Sebuah kantong bagian atas yang buntu mungkin menunjukkan adanya TEF bagian proksimal. Udara di lambung dan usus memastikan adanya TEF bagian distal. Tidak adanya udara di abdomen menunjukkan $\mathrm{AE}$ yang terisolasi tanpa TEF. ${ }^{1,2}$

Diagnosis TEF tanpa AE lebih sulit dan memerlukan tingkat kecurigaan yang lebih tinggi terhadap gejala klinis yang muncul. Diagnosis dapat dibuat dengan esofagografi barium dalam posisi prone. Namun, bronkoskopi ataupun esofagoskopi sering diperlukan untuk menegakkan diagnosis.1,2

insidensi kelainan-kelainan lain yang behubungan dengan EA yang dapat diketahui adalah sekitar 50-70\%, oleh karena itu harus dilakukan pemeriksaan untuk mencari kelaianan-kelaianan lain yang berhubungan seperi ekokardiografi, USG ginjal, analisis kromosom. ${ }^{3}$ 


\section{Atresia esophagus long-gap}

Pada bayi dengan AE-TEF kadangkala yang biasanya EA terisoalasi, kantong bagian atas letaknya tinggi dan jarak antara segmen atas dan bawah jauh sehingga susah untuk menghubungkan keduanya tanpa tension. Definisi long gap hingga sekarang masih belum ada kejelasan karena beraneka ragam cara pengukuran dan penyebutan. ${ }^{3}$

Pada kasus $\mathrm{AE}$ terisoalasi, kebanyakan ahli bedah anak akan melakukan operasi dengan meletakkan tube gastrostomi, diobservasi dalam beberapa waktu, dan dilakukan repair primer yang tertunda, karena dalam beberapa bulan, jarak tersebut akan berkurang karena pertumbuhan spontan, yang mana akan memungkinkan repair primer. ${ }^{1,3}$

\section{Penanganan preoperative}

Pneumonitis dari aspirasi akibat sekresi kantong bagian atas dan refluks dari asam lambung melalui TEFR adalah masalah preoperasi yang paling kritis pada bayi dengan AE-TEF. Penanganan segera termasuk mencegah aspirasi lebih lanjut dan pengobatan dari penumonitisnya. Sebuah kateter suction seharusnya dipasang pada kantong esophageal bagian atas untuk terus mengaspirasi saliva dibawah suction tekanan rendah. Kateter jenis replogle double lumen adala yang terbaik untuk tujuan ini karena perforasi sepanjang sisi kateter terletak hanya dekat dengan ujungnya, yang mana mengurangi kemungkinan penghisapan udara yang teroksigenasi dari laring. Posisi duduk dapat dilakukan tetapi beberapa pihak lebih suka posisi prone, antibiotik spectrum luas dapat diberikan dan fisioterapi pulmonary dapat dimulai. Terapi cairan intravena dengan dekstrose $10 \%$ dan saline hipotonik seharusnya dimulai untuk mempertahankan cairan, elektrolit, dan keseimbangan glukosa. Analog vitamin $\mathrm{K}$ seharusnya diberikan sebelum pembedahan. Intubasi endotrakeal sebaiknya dihindari karena resiko perforasi gaster dan memperburuk distress pernafasan karena perut akan makin kembung karena ventilasi melalui TEF.5,6

Pendekatan operasi pada bayi dengan $\mathrm{AE}$ tergantung pada tipe spesifik kelainan yang timbul dan adanya kelainan yang berhubungan. ${ }^{3}$

\section{INTERPOSISI COLON PADA OESOPHAGEAL REPLACEMENT}

Teknik operasi ${ }^{1,2}$

1. Pasien posisi supine dalam general anesthesia. Pada bahu diletakkan bantalan, posisi leher ekstensi dan menoleh ke kanan. Nasogastrik tube diinsersikan untuk memudahkan diseksi.

2. Pada pasien yang sudah di esofagostomy, diseksi esophagus tidak boleh diperluas melebihi $4-5 \mathrm{~cm}$ ke proksimal untuk menghindari iskemik.

3. Rongga abdomen dicapai dengan melakukan insisi midline. Mobilisasi kolon dilakukan secara hati-hati dibebaskan mulai dari kolon ascenden sampai kolon desenden dan dikeluarkan untuk pemeriksaan suplai pembuluh darah. Graft dipilih dari daerah yang diperdarahi oleh arteri kolika sinistra superior. Biasanya pemisahan arteri kolika media dilakukan dan sebelum pembuluh darah di klem, dilakukan penilaian suplai pembuluh darah.

4. Kemudian kolon direseksi.

5. Jika esophagus tidak direseksi dan rencana dilakukan prosedur bypass kolon, dibuat terowongan dengan melakukan diseksi tumpul pada daerah retrosternal, dipisahkan fasia endotoraks yang dekat dengan sternum, dimulai dari ujung teratas dari insisi di leher setelah dibebaskan dari otot pada suprasternal notch dan pada ujung terbawah dengan melakukan insisi pada bagian posterior dari ujung terbawah sternum. Terowongan diperlebar dengan menggunakan jari secara hati-hati agar tidak mencederai pleura dan benang silik dilewatkan melalui terowongan. Graft colon dilewatkan melalui terowongan yang sudah dibuat.

6. Ujung esophagus diperiksa untuk menghindari striktur pada bagian proksimal. Jika kedua ukuran kolon dan esophagus sama atau tidak terdapat tanda disparitas, maka dilakukan anastomosis end to end dengan menggunakan benang 4/0 yang dapat diserap. Dilakukan anstomosis esofagokolon, dilakukan fiksasi kolon pada otot leher untuk mencegah traksi. Strep muscle dijahit untuk mencegah pembengkakan pada saat menelan. Penutupan luka dilakukan lapis demi lapis dengan meninggalkan drain. 
7. Setelah graf kolon dilewatkan melalui terowongan dan dilakukan esofago-kolon anastomosis, dilanjutkan dengan melakukan anastomosis gastro-kolika dengan dua lapis. Pada kasus retrosternal anastomosis dilakukan pada dinding anterior lambung, dekat dengan antrum dan kolon diletakkan pada posisi yang tepat dan dapat diletakkan lebih tinggi dari pinggir hepar. Kolon harus difiksasi pada pinggir terowongan.

8. Luka operasi ditutup lapis demi lapis dengan meninggalkan drain.

\section{KASUS}

Seorang anak perempuan berumur 1,5 tahun dirawat di bangsal Bedah Anak RSUP Dr. M. Djamil Padang dengan atresia esophagus tipe A Long Gap. Pada saat berumur 1 hari pasien telah dibawa berobat ke IGD RSUP DR M Djamil Padang dengan keluhan keluar liur yang banyak dari mulut sejak lahir, pasien tidak dapat menelan air liur dan ASI dari ibu, kemudian pasien disiapkan untuk operasi pembuatan saluran keluar air liur di leher (esophagostomy) dan pembuatan saluran untuk masuk makanan lewat selang dinding perut (gastrotomy). Kelainan kongenital lain tidak ada. Pasien merupakan anak ke 2, lahir cukup bulan dengan berat badan lahir 3100 gram, spontan, ditolong bidan langsung menangis.

Pada pemeriksaan fisik, anak tampak aktif, terdapat oesophagostomy pada leher sinistra inferior dengan produksi saliva $(+)$, pada abdomen tampak feeding tube di epigastrium. Pasien didiagnosis dengan Post oesophagostomy dan Gastrostomy ai Atresia Oesophagus tipe A, direncanakan untuk dilakukan esophagoplasty dan Interposisi kolon retrosternal. Teknik operasi yang digunakan adalah laparotomy, dilakukan insisi mideline atas dan bawah pusar, setelah peitoneum dibuka Identifikasi kolon asenden, Dilakukan pembuatan graft kolon dengan menggunakan kolon ascenden $1 / 3$ distal, kolon transversum dan 1/3 proksimal kolon descenden. Identifikasi arteri kolika dekstra, arteri kolika media, pedikel diperdarahi oleh atreri mesentrika inferior.

Pada keadaan ini hanya arteri mesentrika inferior yang memperdarahi kolon ascenden dan kolon transversum. Setelah dilakukan penilaian dan evaluasi terhadap pendarahan graft kolon, dilanjutkan dengan menyambung graft kolon dengan esofagus bagian proksimal dengan teknik pull-through di retrosteral. Kemudian dilakukan pembuatan anastomosis cervical, esophagus dicapai dengan akses dari cervical sinistra. Kemudian kolon yang sudah dibebaskan tadi dipindahkan kearah cervical dengan cara pull-through retrosternal. Kemudian dilakukan cervical anastomosis dengan teknik modified two layer end to end anastomosis. Setelah dilakukan pull through graft kolon, dibuat anastomosis antara gaster dan kolon untuk saluran. Untuk anastomosis ini dilakukan anastomosis end to side antara kolon dan gaster.

Rekonstruksi selanjutnya disempurnakan dengan melakukan anastomosis antara bagian kolon asenden yang tersisa dan kolon desenden dengan anastomosis end to end.

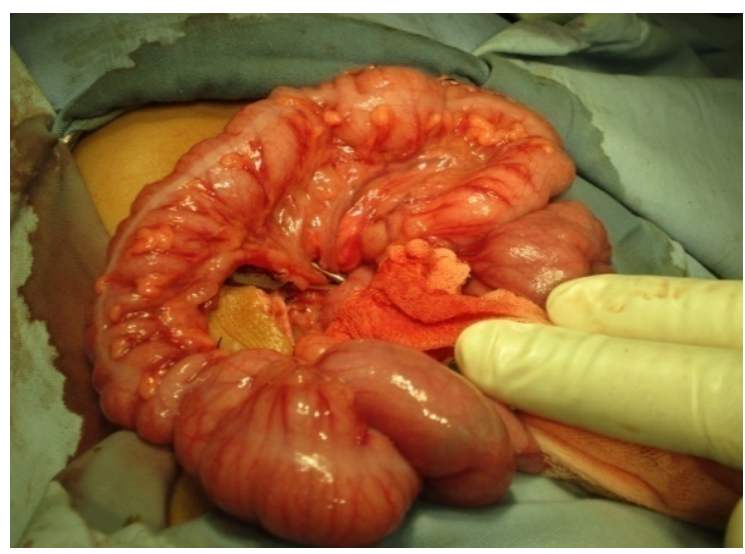

Gambar 2. Identifikasi dan bebaskan kolon ascenden $1 / 3$ distal, kolon transversum dan $1 / 3$ proksimal kolon descenden.

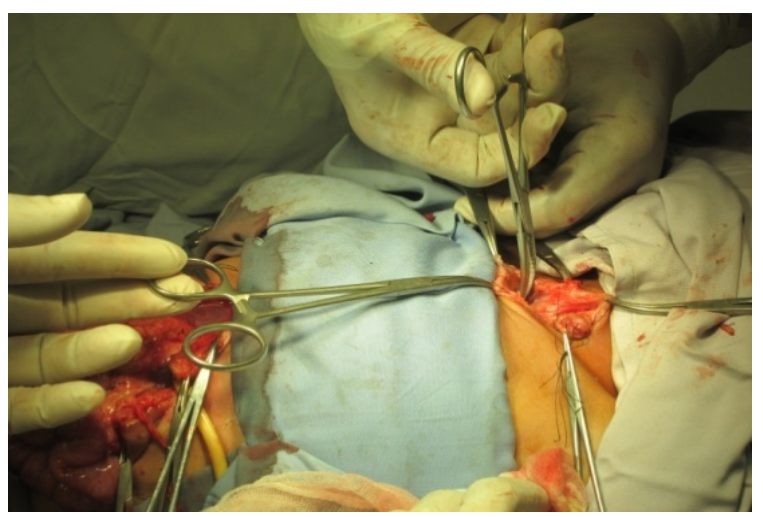

Gambar 3. Esophagus bagian distal 


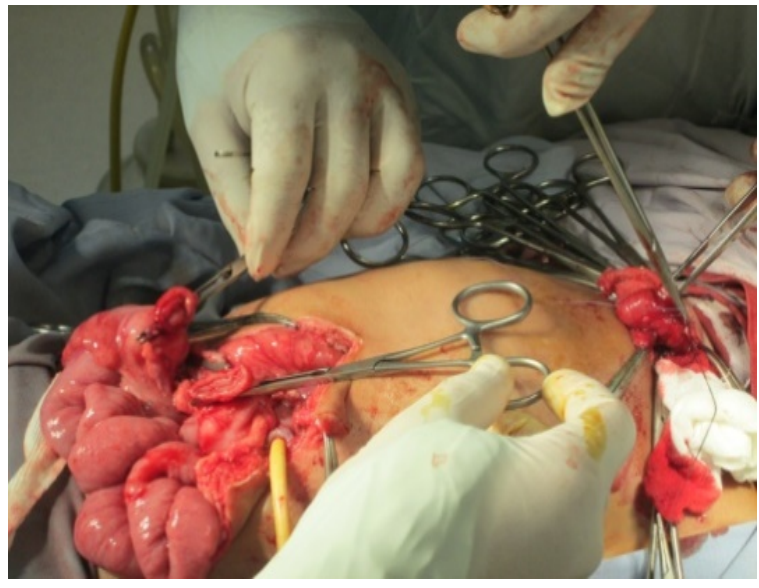

Gambar 4. Segmen kolon yang akan digunakan untuk esophagoplasty

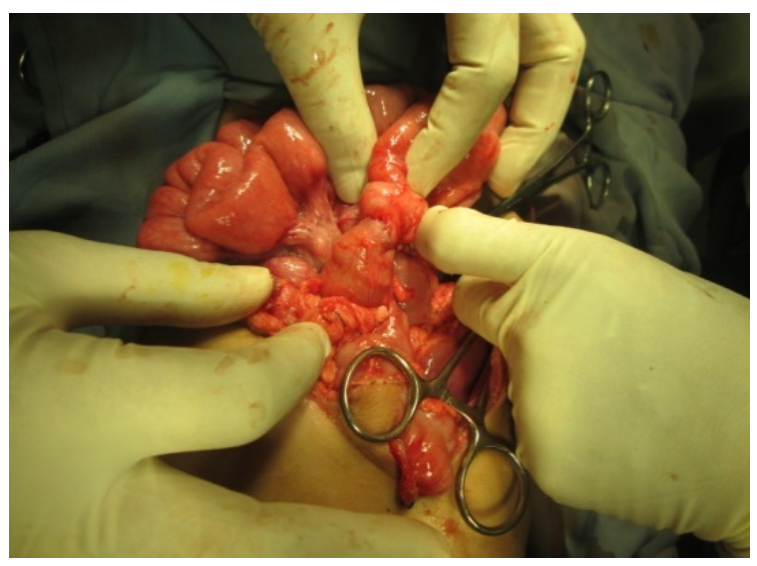

Gambar 5. Anastomose end to end antara esophagus dengan kolon

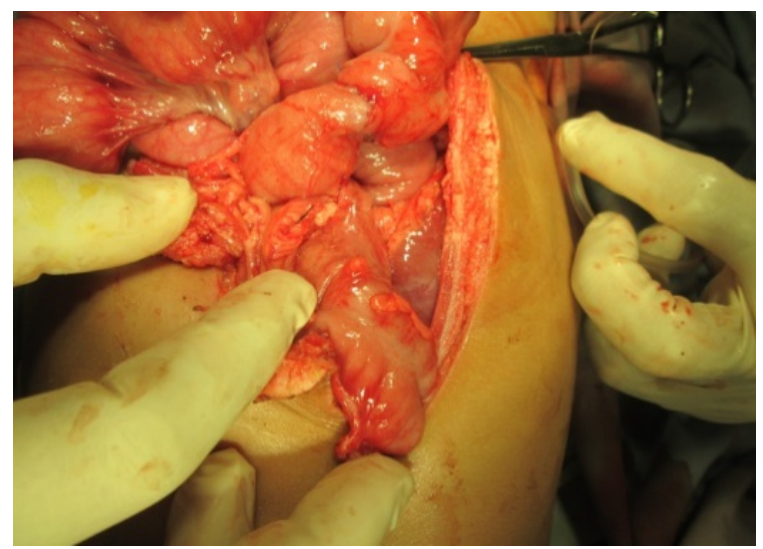

Gambar 6. Anastomose end to side antara kolon dan gaster

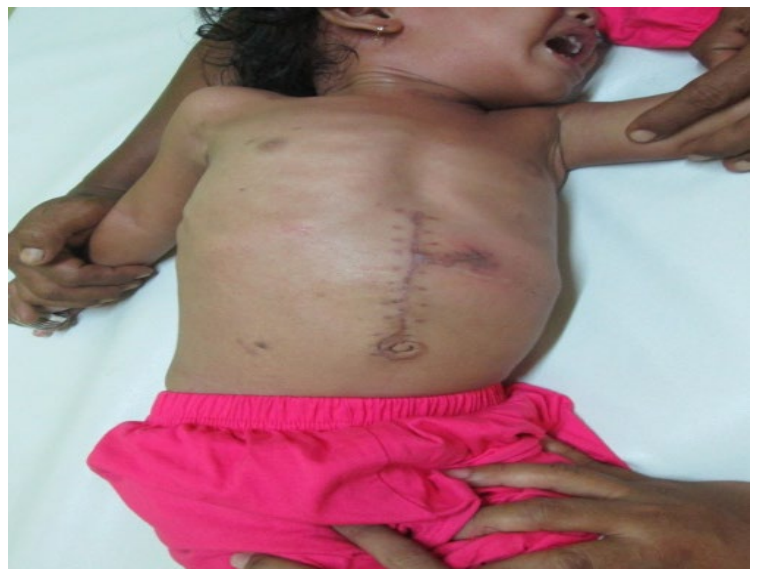

Gambar 7. Kondisi pasien saat pulang dari Rumah Sakit

Pasien post operatif dirawat di ICU sampai hari ke-5, kemudian dipindahkan ke ruangan rawat bedah. Diet enteral dimulai hari ke-6 dan dinaikkan secara bertahap. Pasien dipulangkan hari ke 14 dengan kondisi luka baik dan sudah diberikan makanan lunak.

\section{PEMBAHASAN}

Pasien perempuan yang didiagnosa dengan atresia esophagus tipe A Long Gap saat berumur 1 hari, ditegakkan melalui pemeriksaan $x$-ray dimana dilakukan pemasangan OGT dengan kontras, pada pasien dilakukan tindakan esophagostomi dan gastrostomi. Kondisi membaik, tidak ditemui kelainan kongenital lain. Pasien bertahan sampai umur 1 tahun 6 bulan. Kemudian pasien disiapkan untuk tindakan transposisi colon retrosternal dan esofagoplasty. Post operatif pasien dirawat di ICU selama 5 hari. Setelah pemberian Total Per Enteral (TPN), diet enteral dimulai hari ke-6 dan dinaikkan secara bertahap. Pasien dipulangkan hari ke 14 dengan kondisi luka baik dan pasien sudah diberikan makanan lunak.

Angka keberhasilan tindakan ini masih rendah, tapi dengan perawatan pasca operatif yang optimal dapat memberikan hasil yang baik dan mencegah komplikasi kebocoran dari anastomose kolon. 


\section{SIMPULAN}

Tindakan Esophagoplasty dengan interposisi kolon retrosternal pada kasus atresia esophagus long gap memberikan hasil yang lebih baik dibandingkan dengan menunggu hingga jarak gap (segmen atas dan segmen bawah) berkurang karena pertumbuhan spontan, yang memungkinkan dilakukan repair primer.

\section{DAFTAR PUSTAKA}

1. Burge DM, Griffiths DM, Steinbrecher HA, Wheeler RA. Pediatric Surgery. Southampton: Hodder Arnold;2005.
2. Grosfeld JL, et al. Pediatric surgery. Philadelphia: Mosby Elsevier;2006.

3. Caty MG. Complication in Pediatric Surgery. New York: Informa Healthcare;2009.

4. Puri PM, Hollwarth E. Springer atlas of pediatric surgery, Berlin Heidelberg, Germany: Springer;2006.

5. Mattei P. Fundamentals of pediatric surgery. Philadelphia: Springer;2010.

6. Arensman RM, Bambini DA, Almond PS. Pediatric Surgery. Texas: Landes Bioscience.2000 